\title{
Influence of a Maximal Incremental Test Until Exhaustion on the Urinary Excretion of Steroid Hormones in Trained Cyclists
}

\author{
by \\ Víctor Toro-Román ${ }^{1}$, Diego Muñoz², Jesús Siquier-Coll ${ }^{1}$ \\ Ignacio Bartolomé1, María Concepción Robles², \\ Marcos Maynar-Mariño ${ }^{1}$
}

This study aimed to assess the effect of a maximum incremental stress test through urinary concentrations of steroid hormones in trained cyclists. Twenty male cyclists participated in the study $(23.83 \pm 2.3$ years; $1.76 \pm 0.03 \mathrm{~m}$; $66.94 \pm 3.59 \mathrm{~kg}$; training volume: $20.50 \pm 2.35 \mathrm{~h} /$ week). Athletes performed a maximum incremental test until exhaustion on a cycle ergometer and urine samples were collected at three different time points: before, immediately after, and $48 \mathrm{~h}$ after the test. Lactate, creatinine and urinary concentrations of testicular and adrenal androgens were obtained as well as urinary concentrations of glucocorticoid hormones. An increase in lactate was observed after the test $(p<0.01)$. There were decreases in the urinary excretion of androgenic hormones after the test, which were significant in testosterone, androsterone, androstenedione, total adrenal androgen and total testicular androgen $(p<0.05)$. The values were restored after $48 \mathrm{~h}(p<0.05)$. Urinary cortisol concentrations decreased after the test $(p<0.05)$. A decrease was also observed in the ratio of anabolic/catabolic hormones $(p<0.05)$ increasing $48 h$ after the test $(p<0.05)$. Increased acute physical exercise until exhaustion causes variations in the urinary excretions of steroid hormones which were restored $48 \mathrm{~h}$ after exercise. Urinary excretion of steroid hormones could be a valid method of monitoring training loads.

Key words: exercise, androgens, glucocorticoids, stress, recovery.

\section{Introduction}

An intrinsic or extrinsic stimulus causes a biological response, a phenomenon that is defined as stress (Yaribeygi et al., 2017) which greatly impacts the physiological functions of the organism. The role of stress response mediators is to help the body adapt to the stressor thereby accelerating the restoration of homeostasis. The physiological system most sensitive to stress is the neuroendocrine system, which responds to the stress of physical exercise by generating changes in the concentrations of several hormones compared to resting levels (Hackney, 2006). Volume and intensity of physical exercise as well as physical fitness are determinants of the level of activation (Fry et al., 1998).

Hormones influence different biological processes throughout life, causing specific alterations in tissue and physiological processes during important developmental periods. Proper functioning of the endocrine system is essential for optimal performance, adaptation to exercise and maintenance of appropriate body composition (Hagmar et al., 2013). Steroid hormones are involved in the development of the body, sexual differentiation, reproductive physiology, osmoregulation, metabolism, regulation of the hypothalamic-pituitary-gonadal axis and the hypothalamic-pituitary-adrenal axis

\footnotetext{
1 - Department of Physiology, School of Sport Sciences, University of Extremadura, Spain.

2 - Department of Didactics of Musical, Plastic and Corporal Expression, School of Teacher Training, University of Extremadura, Spain.
} 
(Zubeldia-Brenner et al., 2016). Both acute and chronic exercises seem to induce changes in the urinary levels of sex steroid hormones (Timón et al., 2007).

Androgens are steroid hormones with an anabolic function, and are considered indicators of the repair and recovery of deterioration caused by stressful situations (Kraemer et al., 1991). Acute physical exercise has been associated with both decreases in the urinary levels of androsterone and etiocolanolone (Timon et al., 2008). Exercise-induced alterations in hormonal concentrations and hormonal interactions can have a positive influence on muscle hypertrophy and strength (Tarpenning et al., 2001). Glucocorticoids are hormones released by the adrenal glands in a circadian manner in response to physiological signals (Miller and Auchus, 2011), and glucocorticoid secretion is a classic endocrine response to stressful situations (Sapolsky et al., 2000). Performing physical exercise increases urinary cortisol levels (Makras et al., 2005).

Different methods are used to quantify the training load. Hug et al. (2003) reported that steroid biomarkers could be an interesting tool to quantify training loads and exercise-induced stress, however, scientific contributions about urinary excretion of hormones as load markers are limited. Therefore, the objective of the present study was to assess the acute effect of an incremental stress test until exhaustion through the urinary concentrations of steroid hormones in cyclists.

\section{Methods}

\section{Participants}

Twenty male cyclists voluntarily participated in this study $(23.83 \pm 2.32$ years; $1.76 \pm$ $0.03 \mathrm{~m} ; 66.94 \pm 3.59 \mathrm{~kg} ; \%$ body fat $8.57 \pm 1.22$; training volume: $22.50 \pm 2.35 \mathrm{~h} /$ week). All of them were informed about the study objective and gave their informed consent to participate. The protocol was reviewed and approved by the Biomedical Ethics Committee of the University of Extremadura (Spain), following the guidelines of the Helsinki Declaration of Ethics. For the collection and treatment of the samples, a code was assigned to each participant to keep the identity of the subjects anonymous. All mandatory laboratory health and safety procedures complied with the course of the research. The inclusion criteria were: to be male, to have practiced cycling during the last 6 years continuously, to follow a systematic training plan of at least $18 \mathrm{~h}$ a week and not to consume any substances, medications or counter-medications that could interfere with the synthesis metabolism or excretion of steroids.

\section{Experimental protocol and measurements Incremental test}

Participants performed an incremental cycling test on an ergometer (Ergo-metrics 900, Ergoline $\left.{ }^{\circledR}\right)$. All of them followed a similar diet during the study, to avoid any possible influence on the results. In addition, no food was ingested between the three hours before the test and the urine collection after the test. Participants did not exercise two days before and during the study. Prior to the test, they performed a $100 \mathrm{~W}$ warmup for 10 minutes. The trial started at $100 \mathrm{~W}$ and increased by $50 \mathrm{~W}$ every 2 minutes until voluntary exhaustion. The tests were performed in the laboratory at ambient temperature (23-25 ${ }^{\circ} \mathrm{C} ; 45-55 \%$ relative humidity). The physiological ergospirometric variables were monitored with a gas analyzer (MGC, model No. 762014-102) and a heart rate (HR) monitor (Polar ${ }^{\circledR}$ "Vantage M"). All trials were performed at 11 a.m. to avoid the effects of circadian cycles and to obtain homogeneous results. To determine peak variables in the incremental test, two criteria were used: to achieve a plateau in $\mathrm{VO}_{2}$, and not to be able to maintain the desired power. Table 1 shows the results of the incremental test until exhaustion.

\section{Lactate evaluation}

Lactate concentrations were obtained from capillary blood samples. A puncture was performed with a MenaLancetPro lancet on the index finger of each participant before the test, immediately after the test and $48 \mathrm{~h}$ later. The samples were analyzed by Lactate Scout (Biolaster, Guipúzcoa, Spain) with a margin of error of $\pm 0.2 \mathrm{mmol} / \mathrm{L}$.

Urine sample analysis

Urine samples were collected before the test (30 min), immediately after the test (the first urine after exertion) and $48 \mathrm{~h}$ into recovery. All collected samples were frozen at $-20^{\circ} \mathrm{C}$ until further analysis. Interpretation of the analytical data from urine tests requires the density of the 
sample to be in the range of $1,005-1,025 \mathrm{~g} / \mathrm{ml}$, and the $\mathrm{pH}$ to be in the normal range of 4.7-7.8. All the urine samples met these conditions.

Creatinine levels were determined to report steroid concentrations in relation to this urine variable. The analysis was performed using the Sigma's Creatinine 555-A kit and a UNICAM 5625 spectrophotometer. The correction for creatinine was applied following the methodology proposed by Heinegård and Tiderström (1973).

The analyses were performed by gas chromatography-mass spectrometry similar to the methods described in the study by Timón et al. (2007). The equipment used for chromatographic analyses was an HP 5890 SERIES II with MSD 5972 detector, for the analysis of androgens in SIM mode, and a Varian 3800 coupled to a mass-mass spectrometer (ion trap) model Saturn 2000 (gas system/masses/masses), for the detection of glucocorticoids. The chromatographic and detection conditions for the androgen analysis were: the carrier gas used was $\mathrm{He} \mathrm{N}-50$ with Flow: $1 \mathrm{ml} / \mathrm{min}$, split 40 , at temperatures of $280^{\circ} \mathrm{C}$ in the detector and $280^{\circ} \mathrm{C}$ in the injector. An HP-1 (Crosslinked Methyl Silicone Gum) column of 25 $\mathrm{m} \times 0.2 \mathrm{~mm}$ I.D. $\times 0.33 \mathrm{~mm}$ was applied. The oven temperature program was: Initial: $120^{\circ} \mathrm{C}$ for 2 min; $1^{\text {st }}$ Ramp: $20^{\circ} \mathrm{C} / \mathrm{min}$ up to $200^{\circ} \mathrm{C}, 0 \mathrm{~min}$; $2^{\text {nd }}$ Ramp: $5^{\circ} \mathrm{C} / \mathrm{min}$ to $240^{\circ} \mathrm{C}$ for $5 \mathrm{~min}$; $3^{\text {rd }}$ Ramp: $30^{\circ} \mathrm{C} / \mathrm{min}$ up to $300^{\circ} \mathrm{C}$ for $5 \mathrm{~min}$. In the detection, the emission current was 70 and the mass range between 100 and 700 . The chromatographic and detection conditions for the analysis of the glucocorticoids were: the carrier gas used was $\mathrm{He}$ N-50 with Flow: $1 \mathrm{ml} / \mathrm{min}$, split 40, at temperatures of $280^{\circ} \mathrm{C}$ in the detector and $280^{\circ} \mathrm{C}$ in the injector. A $15 \mathrm{~m} \times 0.20 \mathrm{~mm}$ Phase TRB-1 Tracer column was used of I.D. $x 0.10 \mathrm{~mm}$. The oven temperature program was: initial: $120^{\circ} \mathrm{C}, 2$ min; $1^{\text {st }}$ Ramp: $20^{\circ} \mathrm{C} / \mathrm{min}$ up to $240^{\circ} \mathrm{C}$ for $7 \mathrm{~min} ; 2^{\text {nd }}$ Ramp: $20^{\circ} \mathrm{C} / \mathrm{min}$ up to $300^{\circ} \mathrm{C}$ for $5 \mathrm{~min}$. In the detection, the temperature in the Trap was $200^{\circ} \mathrm{C}$, in the Manifold $50^{\circ} \mathrm{C}$ and in the Transfer line $280^{\circ} \mathrm{C}$. The mass range in the detection was between 150 and 650 .

The enzymatic reaction was performed at $60^{\circ} \mathrm{C}$ for $15 \mathrm{~h}$. The steroids were extracted with 2 $\mathrm{mL}$ of diethyl ether by stirring for $30 \mathrm{~min}$. The organic phase was derived with $50 \mu \mathrm{L}$ of MSTFA/NH4I / dithiothritol (1:2:4, v/p/p) at $60^{\circ} \mathrm{C}$ for $30 \mathrm{~min}$ to generate the TMS ether derivatives. A volume of $1 \mathrm{~L}$ of the liquid residue was analyzed by GC-MS to determine free steroids, glucuronide and sulfate conjugates.

The hormones studied were testosterone, epitestosterone, androsterone, etiocholanolone, dihydrotestosterone and their sum as total androgens of testicular origin (TTA). As for the adrenal hormones, the urinary concentrations of androstenedione, dehydroepiandrosterone (DHEA) and the sum of both as total androgens of adrenal origin (TAA) were obtained. Values of cortisol, cortisone, tetrahydrocortisol (THF), tetrahydrocortisone (THE) and their sum as total glucocorticoids (TG) were also obtained.

\section{Statistical analyses}

The program SPSS 20.0 was used for the statistical analysis. The normality of the distribution of the variables was analyzed using the Shapiro-Wilk test and the homogeneity of the variance using the Levene test. Once these requirements were verified, the Wilcoxon test was applied for non-parametric intra-group comparisons. The results are expressed as means \pm standard deviation. A $p<0.05$ was considered statistically significant.

\section{Results}

The main results of the study are shown below. Table 1 reflects the ergospirometric values obtained in the test.

Table 2 shows the lactate concentration and creatinine levels before, immediately after, and $48 \mathrm{~h}$ after the trial.

A higher lactate concentration can be observed after the test in comparison to baseline levels $(p<0.01)$. Besides, the levels returned to the baseline values $48 \mathrm{~h}$ after the test, being statistically different with respect to the values after the trial $(p<0.01)$.

Table 3 presents the urinary concentrations of androgens throughout the study.

There was a decrease in all values after the test compared to previous values, being statistically significant in the following variables: testosterone, androsterone and TTA $(p<0.05)$. After $48 \mathrm{~h}$, the concentrations rose, presenting higher values than at baseline, which were statistically significant in testosterone, androsterone, epitestosterone and TTA $(p<0.05)$. 
Regarding the adrenal androgens, a lower concentration was obtained after the test compared to previous concentrations, being statistically significant in the values of androstenedione and in TAA $(p<0.05)$. After $48 \mathrm{~h}$ there was an increase, which was significant in androstenedione and in TAA $(p<0.05)$.

Table 4 presents the urinary concentration of glucocorticoids during particular measurements.

Table 1

Ergospirometric variables of the incremental exercise test.

\begin{tabular}{|c|c|c|c|c|c|c|c|}
\hline & $\begin{array}{l}\text { Time } \\
(\mathrm{min})\end{array}$ & $\begin{array}{l}\text { Load } \\
(W)\end{array}$ & $\begin{array}{l}\text { HR } \\
\text { (beat/min) }\end{array}$ & $\begin{array}{l}\mathrm{VO}_{2 \max } \\
(\mathrm{mL} / \mathrm{kg} / \mathrm{min})\end{array}$ & $\begin{array}{l}\mathrm{VCO}_{2 \max } \\
(\mathrm{L} / \mathrm{min})\end{array}$ & $\begin{array}{l}\mathrm{VE} \\
(\mathrm{L} / \mathrm{min})\end{array}$ & RER \\
\hline Test & $15.93 \pm 4.25$ & $364 \pm 53.3$ & $182 \pm 6$ & $67.53 \pm 7.3$ & $5.07 \pm 0.7$ & $141.1 \pm 27.5$ & $1.13 \pm 0.05$ \\
\hline
\end{tabular}

HR: heart rate; $V O_{2 m a x}$ maximum oxygen consumption;

$V_{C O}$ max: maximum volume of carbon dioxide produced; VE: expiratory volume;

RER: Respiratory Exchange Ratio.

Table 2

Lactate and urinary creatinine concentrations obtained before, immediately after and $48 \mathrm{~h}$ after the incremental exercise test.

\begin{tabular}{llll}
\hline & Before & After & 48 h post exercise \\
\hline Lactate $(\mathrm{mmol} / \mathrm{L})$ & $1.78 \pm 0.34$ & $9.82 \pm 1.67^{* *}$ & $1.52 \pm 0.28^{\wedge \wedge}$ \\
Creatinine $(\mathrm{mg} / \mathrm{mL})$ & $1.03 \pm 0.41$ & $1.16 \pm 0.22$ & $0.98 \pm 0.2$ \\
\hline
\end{tabular}

${ }^{* *}: p<0.01$ differences before vs. after; ${ }^{\wedge}: p<0.01$ differences after $v s .48$ host exercise.

Table 3

Urinary androgen concentrations expressed as ng steroid/mg creatinine, before, immediately after and $48 \mathrm{~h}$ after the stress test.

\begin{tabular}{llll}
\hline & Before & After & 48 h post exercise \\
\hline Testosterone $(\mathrm{ng} / \mathrm{mg})$ & $37.5 \pm 16.5$ & $21.2 \pm 8.9^{*}$ & $99.8 \pm 48.95^{+\wedge}$ \\
Androsterone $(\mathrm{ng} / \mathrm{mg})$ & $2460.2 \pm 993.1$ & $1624.4 \pm 819.2^{*}$ & $3701.9 \pm 378.2^{+\wedge}$ \\
Etiocholanolone $(\mathrm{ng} / \mathrm{mg})$ & $1105.5 \pm 619.8$ & $848.6 \pm 340.1$ & $1177.1 \pm 591.8$ \\
Epitestosterone $(\mathrm{ng} / \mathrm{mg})$ & $55.8 \pm 29.3$ & $35.5 \pm 13.9$ & $119.8 \pm 34.71^{+\wedge}$ \\
Dihydrotestosterone (ng/mg) & $49.7 \pm 25.8$ & $42.7 \pm 24.3$ & $68.1 \pm 49.92$ \\
TTA (ng/mg) & $3708.7 \pm 1503.1$ & $2572.4 \pm 772.3^{*}$ & $5166.7 \pm 807.1^{+\wedge}$ \\
DHEA (ng/mg) & $197.1 \pm 85.3$ & $154.1 \pm 62.3$ & $218.5 \pm 119.9$ \\
Androstenedione (ng/mg) & $32.1 \pm 13.7$ & $10.4 \pm 4.4^{*}$ & $41.9 \pm 21.8^{\wedge}$ \\
TAA (ng/mg) & $229.2 \pm 120.3$ & $164.5 \pm 134.3^{*}$ & $260.4 \pm 134.4^{\wedge}$ \\
\hline
\end{tabular}

*: $p<0.05$ differences before vs. after; $\wedge$ : $p<0.05$ differences after $v$ s. 48 h post exercise; $+: p<0.05$ differences before vs. 48 h post exercise; TTA: total testicular androgens; DHEA: dehydroepiandrosterone; TAA: total adrenal androgens. 
Table 4

Urinary concentrations of glucocorticoids expressed as ng steroid/mg creatinine, before, immediately after and $48 \mathrm{~h}$ after the incremental exercise test.

\begin{tabular}{llll}
\hline & Before & After & 48 h post exercise \\
\hline THE (ng/mg) & $1698.3 \pm 932$ & $1843.1 \pm 980$ & $1917.6 \pm 1135.5$ \\
THF (ng/mg) & $1470.2 \pm 865$ & $1228.1 \pm 695$ & $1364.5 \pm 780.6$ \\
Cortisone (ng/mg) & $85.5 \pm 32.7$ & $94.7 \pm 28.9$ & $96.8 \pm 41.7$ \\
Cortisol (ng/mg) & $127.9 \pm 50.9$ & $85.1 \pm 32.5^{*}$ & $109.8 \pm 55.6$ \\
TG (ng/mg) & $3381.9 \pm 1560$ & $3251 \pm 1486$ & $3488.7 \pm 1551.3$
\end{tabular}

*: $p<0.05$ differences before vs. after; THE: tetrahydrocortisone; THF: tetrahydrocortisol; TG: total glucocorticoids.

Table 5

Variations in the ratio of anabolic/catabolic hormones before, immediately after and $48 \mathrm{~h}$ after the stress test.

\begin{tabular}{llll}
\hline & Before & After & 48 h post exercise \\
\hline TTA/TG & $1.1 \pm 0.30$ & $0.79 \pm 0.40$ & $1.48 \pm 0.5^{\wedge}$ \\
& & & \\
TAA/TG & $0.06 \pm 0.03$ & $0.05 \pm 0.02$ & $0.07 \pm 0.02$ \\
Testosterone/Cortisol + Cortisone & $0.17 \pm 0.04$ & $0.12 \pm 0.03$ & $0.48 \pm 0.06^{+\wedge}$ \\
DHEA/Cortisol + Cortisone & $0.92 \pm 0.10$ & $0.86 \pm 0.15$ & $1.06 \pm 0.2^{\wedge}$
\end{tabular}

$\wedge: p<0.05$ differences after vs. 48 h post exercise; $+: p<0.05$ differences before vs. 48 h post exercise;

TTA: total testicular androgens; DHEA: dehydroepiandrosterone; TAA: total adrenal androgens;

TG: total glucocorticoids.

Decreases in urinary concentrations were observed after exercise, except for THE and cortisone concentrations. The decrease in cortisol was statistically significant after exercise $(p<0.05)$. After $48 \mathrm{~h}$, the values rose, without showing significant differences compared to the values obtained in previous measurements.

Table 5 shows the changes in the ratio of anabolic/catabolic hormones in the different measurements obtained.
The values of the ratio decreased after the test compared to the previous values, however, after $48 \mathrm{~h}$, the results were restored, even to above the initial levels, which were significant, except for the value of TAA/TG $(p<0.05)$.

\section{Discussion}

The present study assessed the acute effect of a maximal incremental stress test until exhaustion on the urinary excretion of steroid 
hormones in trained cyclists. This research shows variations in the urinary excretion of steroid hormones after the trial, which were restored within $48 \mathrm{~h}$ after the test. It should be noted that most studies that evaluate alterations in hormones after exercise select blood or saliva samples, so this aspect should be considered when comparing results.

As observed in the results, lactate concentrations increased significantly after testing $(p<0.01)$. It has been documented that exercise intensity increases lactate production and concentration due to limited oxidative phosphorylation of $\mathrm{O}_{2}$ (Gladden, 2004). Lactate is released from the muscle into the blood to be transported to the liver where it is used to synthesize glucose through gluconeogenesis. The concentration of lactate during exercise is a marker of intensity of glycolysis. Lactate could stimulate the production of testosterone in Leydig cells through different mechanisms (Lin et al., 2001). Besides, Brooks (2009) reported that lactate can be an important signaling molecule due to its supposed autocrine, paracrine and endocrine actions.

The values were corrected for creatinine concentration. Creatinine production is proportional to the muscle mass of the individual, and its excretion rates are fairly constant and are not modified by physical exercise or by variations in catabolism in the absence of renal pathology. Therefore, this variable can be used to determine the concentration of urine and the actual urinary excretion of steroid metabolites, eliminating possible differences due to dilution. This is essential because the values may be overestimated if the urine is at a high concentration (Gatti et al., 2005).

In this investigation, urinary levels of testicular androgens varied throughout the study, decreasing after the test, being statistically significant in testosterone, androsterone and TTA $(p<0.05)$. The study by Timon et al. (2008) observed significant decreases after strength exercise in the urinary excretion of testosterone, epitestosterone, androsterone and etiocholanolone in untrained subjects. Similarly, the study conducted by Timón et al. (2007) observed decreases in urinary concentrations of adrenal androgens after a 4 week strength program.

This study observed a higher urinary excretion of androgen hormones at baseline than after exercise, which could be consistent with less muscle use of those hormones (Hansen et al., 2001). This may explain why the urinary excretion values of steroid hormones are higher in sedentary subjects than in athletes (Timon et al., 2008). Sedentary subjects have less muscle mass than athletes, so urinary excretion of androgen hormones may be more significant. The decrease in androgenic hormones after exercise could be due to a rise in the retention of these hormones by the body to generate an anabolic environment to repair the tissues and alleviate fatigue caused by exercise (Cumming, 2000). Narasaka et al. (2000) suggested that the lower urinary excretion of androgens could be the result of a decrease in the elimination of androgens by the liver due to the reduction in liver perfusion accompanied by intense exercise.

Regarding glucocorticoids, the cortisol decrease was statistically significant after exercise $(p<0.05)$. Tsai et al. (2014) observed a lower serum cortisol concentration after strength exercise in young people. Conversely, Popovic et al. (2019) reported higher plasma cortisol levels in all subjects after exercise. Nonetheless, the mentioned study highlighted that the cortisol response depended on the level of training. A similar study to this investigation evaluated the acute effect of a handball game in youth players, observing increases in urinary excretion of cortisone, THF, and TG after the match, while cortisol and THE did not undergo significant changes (Corvillo et al., 2013). In this research, only cortisol decreased significantly and the other variables did not undergo significant modifications. The different results obtained could be due to the type of exercise and the different sport disciplines of the athletes.

The variations in the urinary levels of cortisol could be the result of alterations in the pituitary-adrenocortical axis and an indicator of a state of fatigue or overtraining (Lucía et al., 2001). Increases in urinary excretion of cortisone and THE after exercise would corroborate the hypothesis that the adrenal gland was affected by exercise stress (Lac and Berthon, 2000). It should be noted that although the intensity of the effort was high (until voluntary exhaustion) the duration may have been too short to produce significant differences in urinary glucocorticoid 
levels. In long-term activities, one investigation found elevated plasma cortisol levels related to a high volume rather than the intensity of the exercise (Ronsen et al., 2001). Thus, the total volume of the effort may not have been sufficient for trained subjects to produce significant changes. The lack of significant differences between the initial and final levels of urinary glucocorticoid excretion could also indicate a good adaptation of the subjects to training. Further studies of the intensity and volume relationship are necessary to determine to what extent each factor could affect the steroidal profile. Decreases in the urinary excretion of THF, cortisol and TG could also be related to a lower rate of liver clearance, and greater retention of catabolic hormones by the body. However, further research in needed to define the possible causes.

The anabolic/catabolic hormone ratios decreased after exercise, increasing $48 \mathrm{~h}$ after the test $(p<0.05)$. These results coincide with the study by Marcos-Serrano et al. (2018) who analyzed the urinary profile of steroid hormones in an ironman competition, observing a decrease after the competition, reestablished $24 \mathrm{~h}$ later. The anabolic/catabolic hormones ratio is an equilibrium index between the anabolic activity of androgens and the catabolic activity of glucocorticoids. These results show that glucocorticoid hormones (catabolic) predominate over anabolic hormones after testing, generating a catabolic state which is reversed after $48 \mathrm{~h}$ of recovery. In this respect, decreases in the ratio of urinary androgens/glucocorticoids seem to indicate a state of fatigue (Fischer et al., 1992).

Further studies are required to continue investigating the urinary excretion of hormones after exercise. Current findings should be considered limited due to the small number of subjects, as well as the lack of plasma and/or salivary data to establish relationships with the data obtained through urinary excretion. It would be interesting to analyze urinary excretion at different levels of training.

\section{Conclusions}

A maximal incremental test until exhaustion elicited decreases in the urinary concentrations of androgenic hormones, of both testicular and adrenal origin, as well as variations in glucocorticoid hormones, which resulted in a decrease in the ratio of anabolic/catabolic hormones. The values were restored $48 \mathrm{~h}$ after the test, even in a higher proportion than the previous values.

The evaluation of urinary steroids can be a valid and non-invasive method to monitor the stress generated by different types of physical exertion. Urinary excretion of steroid hormones analyzed before and after exercise can determine training-induced fatigue. In addition, this method could provide useful information to adjust the training load.

\author{
Abbreviations \\ DHEA: dehydroepiandrosterone \\ TAA: total adrenal androgens \\ TG: total glucocorticoids \\ THE: tetrahydrocortisone \\ THF: tetrahydrocortisol \\ TTA: total testicular androgens
}

\title{
Acknowledgements
}

We thank all the participating cyclists for their excellent cooperation during the data collection.

\section{References}

Brooks GA. Cell-cell and intracellular lactate shuttles. J Physiol, 2009; 587(23): 5591-5600

Corvillo M, Timón R, Maynar M, Brazo-Sayavera J, Maynar JI. Urinary excretion of steroid hormones after a female handball match. Rev Int Med Cienc Act Fís Deport, 2013; 13(52): 737-747 
Cumming D. The male reproductive system, exercise, and training.In Sports Endocrinology, Springer, 119-131, 2000

Fischer HG, Hartmann U, Becker R, Kommans B, Mader A, Hollmann W. The excretion of 17-ketosteroids and 17-hydroxycorticosteroids in night urine of elite rowers during altitude training. Int J Sports Med, 1992; 13(01): 15-20

Fry AC, Kraemer WJ, Ramsey LT. Pituitary-adrenal-gonadal responses to high-intensity resistance exercise overtraining. J Appl Physiol, 1998; 85(6): 2352-2359

Gatti R, Cappellin E, Zecchin B, Antonelli G, Spinella P, Mantero F, De Palo EF. Urinary high performance reverse phase chromatography cortisol and cortisone analyses before and at the end of a race in elite cyclists. J Chromatogr B, 2005; 824(1-2): 51-56

Gladden LB. Lactate metabolism: a new paradigm for the third millennium. J Physiol, 2004; 558(Pt 1): 5

Hackney AC. Stress and the neuroendocrine system: the role of exercise as a stressor and modifier of stress. Expert Rev Endocrinol Metab, 2006; 1(6): 783-792

Hagmar M, Berglund B, Brismar K, Hirschberg AL. Body composition and endocrine profile of male Olympic athletes striving for leanness. Clin J Sport Med, 2013; 23(3): 197-201

Hansen S, Kvorning T, Kjaer M, Sjøgaard G. The effect of short-term strength training on human skeletal muscle: the importance of physiologically elevated hormone levels. Scand J Med Sci Sports, 2001; 11(6): 347-354

Heinegård D, Tiderström G. Determination of serum creatinine by a direct colorimetric method. Clin Chim Acta, 1973; 43(3): 305-310

Hug M, Mullis PE, Vogt M, Ventura N, Hoppeler H. Training modalities: over-reaching and over-training in athletes, including a study of the role of hormones. Best Pract Res Clin Endocrinol Metab, 2003; 17(2): 191-209

Kraemer W, Gordon S, Fleck S, Marchitelli L, Mello R, Dziados JE, Friedl, K Harman, E Maresh, C, Fry A. Endogenous anabolic hormonal and growth factor responses to heavy resistance exercise in males and females. Int J Sports Med, 1991; 12(02): 228-235

Lac G, Berthon P. Changes in cortisol and testosterone levels and $\mathrm{T} / \mathrm{C}$ ratio during an endurance competition and recovery. J Sports Med Phys Fitness, 2000; 40(2): 139

Lin H, Wang SW, Wang RY, Wang PS. Stimulatory effect of lactate on testosterone production by rat Leydig cells. J Cell Biochem, 2001; 83(1): 147-54

Lucía A, Díaz B, Hoyos J, Fernández C, Villa G, Bandrés F, Chicharro JL. Hormone levels of world class cyclists during the Tour of Spain stage race. Br J Sports Med, 2001; 35(6): 424-30

Makras P, Koukoulis GN, Bourikas G, Papatheodorou G, Bedevis K, Menounos P, ... Kartalis G. Effect of 4 weeks of basic military training on peripheral blood leucocytes and urinary excretion of catecholamines and cortisol. J Sports Sci, 2005; 23(8): 825-834

Marcos-Serrano M, Olcina G, Crespo C, Brooks D, Timon R. Urinary Steroid Profile in Ironman Triathletes. J Hum Kinet, 2018; 61(1): 109-117

Miller WL, Auchus RJ. The molecular biology, biochemistry, and physiology of human steroidogenesis and its disorders. Endocr Rev, 2011; 32(1): 81-151

Narasaka T, Moriya T, Endoh M, Suzuki T, Shizawa S, Mizokami Y, Matsouka, T, Sasano H. $\beta$ hydroxysteroid dehydrogenase type 2 and dehydroepiandrosterone sulfotransferase in the human liver. Endocr J, 2000; 47(6): 697-705

Popovic B, Popovic D, Macut D, Antic IB, Isailovic T, Ognjanovic S, Bogavac T, Kovacevic VE, Ilic D, Petrovic M. Acute Response to Endurance Exercise Stress: Focus on Catabolic/Anabolic Interplay Between Cortisol, Testosterone, and Sex Hormone Binding Globulin in Professional Athletes. J Med Biochem, 2019; 38(1): 6-12 
Ronsen O, Haug E, Pedersen BK, Bahr R. Increased neuroendocrine response to a repeated bout of endurance exercise. Med Sci Sports Exerc, 2001; 33(4): 568-575

Sapolsky RM, Romero LM, Munck AU. How do glucocorticoids influence stress responses? Integrating permissive, suppressive, stimulatory, and preparative actions. Endocr Rev, 2000; 21(1): 55-89

Tarpenning KM, Wiswell RA, Hawkins SA, Marcell TJ. Influence of weight training exercise and modification of hormonal response on skeletal muscle growth. J Sci Med Sport, 2001; 4(4): 431-446

Timón R, Maynar M, Muñoz D, Olcina GJ, Caballero MJ, Maynar JI. Variations in urine excretion of steroid hormones after an acute session and after a 4-week programme of strength training. Eur J Appl Physiol, 2007; 99(1): 65-71

Timon R, Olcina G, Maynar M, Muñoz D, Caballero MJ, Maynar JI. Evaluation of urinary steroid profile in highly trained cyclists. J Sports Med Phys Fitness, 2008; 48(53): 4

Timon R, Olcina G, Muñoz D, Maynar JI, Caballero MJ, Maynar M. Determination of urine steroid profile in untrained men to evaluate recovery after a strength training session. J Strength Cond Res, 2008; 22(4): 1087-1093

Tsai C-L, Wang C-H, Pan C-Y, Chen F-C, Huang T-H, Chou F-Y. Executive function and endocrinological responses to acute resistance exercise. Front Behav Neurosci, 2014; 8262

Yaribeygi H, Panahi Y, Sahraei H, Johnston TP, Sahebkar A. The impact of stress on body function: A review. EXCLI J, 2017; 161057

Zubeldia-Brenner L, Roselli CE, Recabarren SE, Gonzalez Deniselle MC, Lara HE. Developmental and functional effects of steroid hormones on the neuroendocrine axis and spinal cord. J Neuroendocrinol, $2016 ; 28(7)$

\section{Corresponding author:}

\section{Diego Muñoz}

Department of Didactics of Musical, Plastic and Corporal Expression, School of Teacher Training, University of Extremadura, Spain.

Phone: +34 927257460 (ext. 57833)

E-mail: diegomun@unex.es 